\title{
LA NOBLEZA CACERENSE EN LOS SIGLOS XIII-XV
}

\author{
POR \\ SANTOS BENITEZ FLORIANO
}

\section{A) Prólogo}

LA comunicación que presento a este primer simposio sobre «Las Armas en la Historia» lleva por título La nobleza cacerense en los siglos XIII-XV.

En primer lugar, me gustaría señalar que este trabajo no es un estudio genealógico de la misma, del que ya se han ocupado importantes investigadores; pretende ser un análisis sobre algunos aspectos o funciones políticas, sociales y económicas que tradicionalmente se estudian como propios de la clase nobiliaria hispanocristiana en este período histórico sacados de una serie de documentos que se encuentran en el Archivo Municipal de Cáceres y que tienen relación con la nobleza cacereña.

A través de ellos hemos investigado este espíritu de la nobleza cacerense intentando conocer mejor su forma de vida, similar, como veremos, a la del resto de la nobleza de la España cristiana del momento.

\section{B) INTRODUCCIÓN}

Tomando como guía el libro de Antonio C. Floriano Cumbreño Documentación bistórica del Archivo Municipal de Cáceres, tomo I (Cáceres, 1934), hemos realizado la consulta e investigación de una serie de trece documentos que hemos considerado idóneos para el estudio de la nobleza cacereña desde el año 1273 hasta 1493, fechas estas del primero y del último documento manejado.

Debido a que algunos documentos se encontraban en mal estado y otros, aunque catalogados por Floriano en su día, hoy están perdidos, hemos recurrido a copias de los mismos utilizando el Libro Becerro y el libro Fueros y privilegios de Cáceres, atribuido a Ulloa Golfín.

Diremos para los que no los conozcan que el Libro Becerro es una recopilación de documentos de los siglos XIII, XIV y XV copiados en letra 
cortesana y con un total de 365 páginas, y Fueros y privilegios de Cáceres es otra compilación de documentos que van desde el Fuero concedido a Cáceres por Alfonso IX en 1229 hasta cartas o correspondencia del reinado de Felipe IV escritos en letra de imprenta y con 416 páginas de contenido.

Metidos ya de lleno en nuestro estudio, hemos de anotar que la nobleza cacereña aparece muchas veces nombrada en el Fuero Latino de Cáceres con los nombres de mílites, infanzones, nóbiles, potestates, caballeros, etc. Y de su importancia nos da buena prueba Fernán Mexía, que en el siglo xv nos señalaba que la villa de Cáceres era desde fines de la Edad Media uno de los cuatro principales solares de nobleza de España (Fernán Mexía, Libro intitulado Nobiliario perfectamente copilado $i$ ordenado por cl onrrado cavallero feranid Mexia veynte quatro de Jaben, sábado $30 \mathrm{dc}$ junio de 1492).

Hemos analizado cinco aspectos fundamentales para el estudio de la nobleza cacereña:

1) La exención de pechar.

2) El espíritu de clase nobiliaria.

3) El espiritu guerrero.

4) El acceso de la nobleza a la Administración municipal (a los cargos municipales).

5) Los abusos de la nobleza cacereña.

\section{1) LA EXENCIÓN DE PECHAR}

La nobleza cacereña destacaba del resto de la población libre por su situación de privilegio y por su poder económico, político y social. Uno de los privilegios más importantes era el de no pagar tributos ni impuestos, recogido en cl Fuero de Cáceres.

Esta exención la hemos analizado, en la realidad, a través de tres documentos:

a) El primero de ellos es una carta abierta del rey don Alfonso $\mathrm{X}$ (catalogada por Floriano con el número 9 D. O.) dada en Toledo el 12 de febrero era cle 1311 años, o sea, de 1273, en la cual el rey determina que por el gran servicio que le hizo el Concejo de Cáceres al infante don Fernando, su hijo, cuando fueron con él a Granada, tenía a bien conceder que todos los caballeros de la villa que vinieran a vejez o a pobreza, o si tuvieran caballo y armas para la guerra, y a las viudas de los caballeros, sean excusados de pecho, diciendo en ella respecto a los que pudieran infringir su carta lo siguiente: «E defiendo que njnguno sea osado de les pasar 
contra ello, en qualquier que lo fisiese pecharme en pena çient maravedis, e a ellos todo el daño doblado» (Libro Becerro, pág. 212).

b) El 12 de dicicmbre de 1471, Enrique IV concedió un albalá (catalogado por Floriano con el número 123 D. C. L. B.) al Concejo y particulares de Cáceres en el que hacía constar que por los leales servicios que los caballeros, escuderos y vecinos y moradores de Cáceres le hicieron al recuperar la villa de Cáceres para el rey, poniendo en peligro para ello sus personas y haciendas cuando la ocupó don Gomes de Solís, maestre de Alcántara, les concedía que no pagaran alcabala alguna de todas las hierbas de las dehesas para siempre jamás. Este documento nos da idea de que hasta entonces era pagada la dicha alcabala.

c) Este albalá fue confirmado por Enrique IV a través de un privilegio dado en Segovia el 18 de diciembre de 1471 (catalogado por Floriano con el número 124 D. C. L. B.). El rey señala que pagarán tres mil maravedís cada uno de los que lo contrario hicieran, dinero que pasaría a la cámara real de su majestad.

\section{2) El espíkitu de CLASE NOBILIARIA}

Uno de los aspectos más importantes de la clase nobiliaria a principios del siglo Xiv era su unión como grupo, puesta de manifiesto cuando formaron la Hermandad de los Caballeros, fijosdalgos y hombres buenos de las ciudades, villas y lugares en 1315 para protegerse contra los abusos de los tutores del rey Alfonso XI y velar por sus derechos.

Las Hermandades, como señala García de Cortázar, aparecen como la versión de acción política directa que promueven los grupos, en este caso el nobiliario, cuando se consideran agraviados por alguna razón (J. A. Gar-

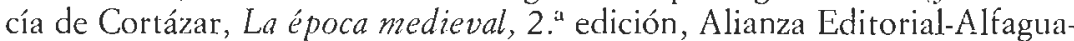
ra, Madrid, 1974, págs. 456-457), siendo de muchos tipos, dependiendo del grupo que los promueva.

Acerca de la constitución de esta Hermandad, poseemos la copia en el Libro Becerro (catalogado por Floriano con el número 39 D. C. L. B.) del Cuaderno de las Cortes, celebradas en Burgos el 2 de julio era de 1353 (año 1315) fechado, en el que aparece la formación de la citada Hermandad para defenderse de la reina doña María de Molina y de los infantes don Juan y don Pedro, tutores de Alfonso XI.

El número de las ciudades, villas y lugares que la constituyeron fue de cien, y la nobleza de Cáceres estuvo presente, sintiéndose unida al resto de la corona, a través de los procuradores Sancho Sánchez y Sancho Pasqual.

En esta copia se puede leer cómo esta Hermandad pretendía que to- 
Gladius, Vol. especial (1988), pp. 13-20

dos fueran uno, un solo corazón y una sola voluntad para guardar sus señoríos, el servicio del rey y todos sus derechos.

\section{3) EL ESPÍRITU GUERRERO}

En el Fuero de Cáceres se dicta como aspecto fundamental de la nobleza el de que tenían caballo y armas siempre dispuestos para la guerra.

La función guerrera, según Domínguez Ortiz, era la función más propia de la nobleza, y de ella derivaba teóricamente la mayoría de sus exenciones y privilegios (Antonio Domínguez Ortiz, Las clases privilegiadas en la España del Antiguo Régimen, Ediciones Istmo, Madrid, 1973, página 143).

Esta vocación guerrera se mantuvo muy fuerte durante toda la Baja Edad Media.

Los caballeros amaban el riesgo y la aventura y siempre estaban deseosos de luchar. Unas veces peleaban junto al rey, pero en períodos donde no había guerra se debatían en luchas feroces en sus villas entre los distintos clanes nobiliarios intentando saciar de este modo su belicosidad. Y en la villa de Cáceres no eran ajenos los grupos nobiliarios a estos enfrentamientos.

Respecto al primer aspecto, que hemos expuesto, de guerras de ayuda al rey, lo observamos a través de una real carta de los Reyes Católicos (catalogada por Floriano con el número 160 D. O.) dada el 31 de julio de 1485 en Córdoba, por la que solicitaba se reclutara gente de armas en la villa y su tierra con destino a la guerra de Granada. Pedía el rey sesenta hombres de a caballo y seiscientos peones, doscientos ballesteros y los otros cuatrocientos lanceros. Diciendo a continuación que el grupo «venga con el Corregidor, e con el pendon de essa villa, e venga con la dicha gente todos los Regidores y Caualleros, escuderos de cinquenta años abaxo» (Fueros y privilegios de Cáceres, pág. 312). Muestra, por último, don Fernando que el que no fuere quedaría privado de su oficio y se le confiscarían sus bienes.

Por lo que se refiere a los enfrentamientos entre los grupos nobiliarios, podemos afirmar que Cáceres los padecía. Veamos dos muestras de ello:

a) A través de unas ordenanzas dictadas por la Reina Católica en Cáceres, el 9 de julio de 1477 (catalogadas por Floriano con el número $130 \mathrm{D}$. O.), pretendía pacificar la tierra y reprimir los bandos y parcialidades de la villa. La Reina señala en ellas, ante los continuos atropellos que se venían sucediendo, que «todos juntamente favorescan la justicia, que a la sazon fuere en esta villa». También apuntaba «que ningunas 
personas, vezinos e moradores desta dicha villa e su tierra e arravales no se armen nj acudan a vandos, nj a sonadas, nj a rruidos, en favor de los cavalleros e escuderos desta dicha villa». En estas ordenanzas, asimismo, se dan normas acerca de cómo se debían construir los edificios y acerca de ciertas modificaciones de las casas fuertes de los nobles para evitar que fueran centros inexpugnables, ordenando, entre otras, «que todas las torres cjue estan començadas a faser en esta dicha villa e sus arravales, sy sus dueños qujsieren alçarlas que lo puedan faset, solamente hasta los tejados de la casa de morada e non mas» (Libro Becerro, pág. 285v). Se produce, como vemos, un cambio en la arquitectura civil cacereña a tines del siglo $\mathrm{xv}$.

b) Por una real provisión de los Reyes Católicas, dada en Córdoba el día 5 de diciembre de 1491 (catalogada por Floriano con el número 243 D. O.), se prohibía a los regidores y caballeros cacereños que tuvietan allegados para resolver sus diferencias, imponiendo la pena de tres mil maravedís por cada vez que esta provisión no se cumpliera y, además, que el que lo hiciera fuera desterrado de la villa y su tierra per seis meses. Asimismo, los Reyes ordenaban que los caballeros no tomaran por allegados suyos a los concejos de la dicha tierra, ya que recibían de ellos dádivas y presentes, bajo pena de destierro de la villa y tierra y pago de tres mil maravedís por cada vez.

\section{4) El acceso de la nobleza a la Administración municipal (A LOS CARGOS MUNICIPALES)}

Debemos recordar que en la Baja Edad Media se facilitó la irrupción de la nobleza en los concejos.

Apunta Colmeiro: "Luego que las ciudades crecieron en poder y riqueza, ofreció el gobierno municipal cebo apetitoso a la ambición y la codicia» (Curso de Derecho Polílico).

La nobleza llegó a tener el monopolio legal de los cargos municipales de mayor importancia en la mayoría de las ciudades castellanas de ese tiempo, y el Concejo de Cáceres no fue, una vez más, la excepción.

a) La Reina Católica, en su estancia en Cáceres en el año 1477, dictó una ordenanza (catalogada por Floriano con el número 129 D. O.) determinando la constitución que habría de tener el ayuntamiento cacereño, enumerando los cargos que dirigirían al mismo y por medio de qué normas se elegirían éstos. Esta ordenanza fue dada en Cáceres el 9 de julio de 1477. La Reina mandó que la villa tuviera:

- Doce regidores, perpetuos, entre los que no fueran pecheros y con un salario de dos mil maravedís por año. 
- Un procurador del Concejo, perpetuo, y con un salario de dos mil maravedís al año.

- Un escribano del Concejo, perpetuo, y con quinientos maravedís al año.

- Un mayordomo y un alférez de la villa, nombrados por un año y con el salario acostumbrado.

- Cuatro contadores de los propios del Concejo.

- Cuatro fieles.

- Un procurador del común, elegido por un año entre los pecheros de la tierra, que entrara en el concejo y procurara el bien de éstos en el ayuntamiento.

b) Dentro de este mismo cuerpo documental se incluye el acta de la ceremonia de elección de los cargos que constituirían el concejo de la villa, ejecutándose de este modo la ordenanza antes mostrada. Esta ceremonia tuvo lugar en Cáceres el 9 de julio de 1477 (catalogada por Floriano con el número $131 \mathrm{D}$. O.). Ni que decir tiene que toda la nobleza en pleno estaba allí para acaparar los cargos municipales. Empezado el acto, la Reina mandó que todos prometieran, juraran e hicieran pleito-homenaje de que todos los oficiales que fueran puestos por su alteza los guardarán, cumplirán y no los impugnarán. Después de hecho el juramento, empezó la elección de los doce regidores entre cuarenta y ocho caballeros hidalgos de la villa, veinticuatro del linaje de arriba («abaxo rriba» en el documento) y veinticuatto del de abajo. Se escribió cada nombre en un papel y se metieron los papeles en dos bonetes. Después la Reina sacó de cada bonete seis papeles, nombrando de este modo a los doce regidores cacereños para toda su vida. Fueron los siguientes:

- Luys de la Peña.

- Garcia de Osma.

- Fernando de Toledo.

- Pedro de Godoy.

- Juan de Orellana.

-_ Cristoval de Figueroa.
- Alvaro de Ribera.

- Gonçalo de Ulloa.

- Francisco de Andrada.

- Francisco de Carvajal.

- Diego de Paredes.

- Juan Delgadillo.

A continuación juntáronse los treinta y seis papelejos restantes en un bonete y de ellos extrajo la Reina uno con el nombre del procurador del Concejo, saliendo Diego Gomes de Torres. Poco después, con cuatro papeles con los nombres de cuatro escribanos públicos, suficientes y hábiles de la villa, sacó el de Diego Hurruco para el puesto de escribano del Concejo.

De este modo se perpetuaron en manos de miembros de la nobleza cacereña los cargos municipales de raigambre; con lo cual, la nobleza hizo 
y deshizo a su antojo en todos los asuntos que se trataban en el concejo, haciendo valer siempre en ellos sus intereses nobiliarios.

\section{5) Los ABUSOS DE LA NOBLEZA CACEREÑ $A$}

El profesor Colmeiro afirmaba sobre esto: «La cobranza de los pechos y servicios reales, los oficios concejiles bien remunerados, la tenencia de los alcázares, las alcaidías de las fortalezas y castillos, el mando de las milicias en campañas, el influjo decisivo en el nombramiento de procuradores a Cortes, todo junto y lo demás que el abuso añadía estimulaba a los nobles a emplear las artes de la corrupción o los medios de la violencia hasta someter al yugo de su autoridad a los concejos y reducir los vecinos a la humilde condición de sus vasallos» (Curso de Derecho Político).

Y algo parecido ocurrió en el Concejo cacereño o, al menos, es lo que se desprende de los siguientes cuatro documentos que hemos analizado.

a) Doña Juana dio en Jaén, el 4 de agosto de 1.489 (catalogada por Floriano con el número 1.97 D. C. L. B.) una carta al Concejo de Cáceres ratificando lo acordado en la ordenanza dada por la reina Isabel en 1477 acerca de que el común de vecinos tuviera un procurador que defendiera sus intereses en el Concejo. A través de este documento se puede apreciar cómo los regidores no consentían que los pecheros mantuvieran su procurador, como era preceptivo en las ordenanzas, y lo habían anulado y hasta lo suprimieron del Concejo. Viendo la reina esta petición pechera, dio licencia y facultad al común para que cada año nombraran un procurador. En esta carta se dice que este procurador «pueda entrar en los cabildos e conçejos desa dicha villa e procurar las cosas tocantes al dicho comun, e ser presente al faser los rrepartjmjentos e al contar de las dichas quentas e al desacoto de las dichas dehesas» (Libro Becerro, pág. 359). La pena para el que se lo impidiera era de diez mil maravedís.

b) Como consecuencia de la carta anterior, la reina Isabel dio otra carta, en Jaén, el 4 de agosto de 1.489 (catalogada por Floriano con el número 198 D. O.), por la cual tomaba bajo su guarda, seguro y amparo «al común y omes buenos» de la dicha villa de Cáceres. El común temía que los regidores y caballeros de la villa tomaran represalias por la petición del común a la Reina de que nombrasen un procurador, y entonces solicitaron a la Reina que los amparase, cosa que hizo, concediéndoles esta merced a través de esta carta. En ella manda que los que lo contrario hagan sufrirán las mayores penas civiles y criminales en sus personas y bienes, con pérdida de sus oficios si los tuvieran.

c) Esto mismo observamos en una real provisión dada por los Reyes 
Católicos en Córdoba, el 15 de febrero de 1492 (catalogada por Floriano con el número $250 \mathrm{~F}, \mathrm{D}$. O.), por la que ordenaron que ningún caballero, alcalde, ni oficial arrendara las rentas del Concejo. Ante los Reyes se había presentado una petición, diciendo que algunos caballeros, regidores y oficiales de Cáceres arrendaban rentas del Concejo, lo cual ocasionaba gran daño y perjuicio a la villa, por lo que les suplicaban dieran alguna orden para que estos abusos no se produjeran. En esta real provisión los Reyes muestran cómo este asunto fue tratado en las Cortes de Toledo de 1480 , en la que se dio una ley que lo prohibía. Los Reyes imponían penas de pérdida de oficio a los infractores, con la privación del tercio de sus bienes.

d) Por último, a través de una real provisión dada por los Reyes Católicos en Valladolid, el 1 de julio de 1493 (catalogada por Floriano con el número 273 D. O.), mandan que no se impidiera a los alcaldes de los hijosdalgos echar pecho a algunos vecinos de Cáceres que habían aducido la condición de hidalgos sin serlo. El conún expuso una petición mostrando la existencia de una serie de personas que se decían hijosdalgos sin serlos de verdad para no pagar el pecho, lo que ocasionaba gran perjuicio y daño. Estos eran tapados por algunos regidores y caballeros para que les hicieran algún servicio. Los Reyes dictaminaron que se les obligara a contribuir como personas pecheras que eran. En esta real provisión se dice: «Prender a los sobredichos que asy se desyan hijosdalgo e lo no heran a que pagasen e contribuyesen los dichos pechos librementes.»

Con estos cuatro documentos hemos podido ver cómo el poderío real tenía que alzarse contra el señorial para cortar estos abusos de los señores hacia el común cacereño. 